\title{
Relationship between Bath-related Deaths and Low Air Temperature
}

\author{
Masaru Suzuki ${ }^{1}$, Toshiharu Ikaga ${ }^{2}$ and Shingo Hori ${ }^{1}$
}

\begin{abstract}
:
Objective Bath-related sudden cardiac arrests occur frequently in Japan. Although previous studies have reported that most fatal events occurr in winter, the reason why such events exhibit a seasonal variation has not been elucidated. In this study, we hypothesized that the occurrence of bath-related deaths was correlated with a low air temperature.

Methods This prospective cross-sectional observational study was conducted in the Tokyo Metropolitan area between October 2012 and March 2013. Data were collected for all cases involving the activation of the emergency medical system because of an accident or acute illness related to bathing that occurred in Tokyo during the study period. In particular, elderly ( $\geq 65$ years) cardiac arrest victims who had been found in a bathtub filled with water were enrolled. The relationship between the daily number of cardiac arrest events and the lowest daily air temperature in Tokyo was studied using a nonlinear regression model.

Results A total of 3,624 bath-related events were registered in this study. Among these events, 1,081 deaths of elderly individuals who had been found in a bathtub filled with water were recorded. A close correlation was observed between the daily number of events and the lowest daily air temperature. This correlation was described by the following equation: $\mathrm{y}=8.38 \mathrm{e}^{-0.07 x}$, where $\mathrm{y}$ was the daily number of cardiac arrests and $\mathrm{x}$ was the lowest daily air temperature.
\end{abstract}

Conclusion A low air temperature was closely correlated with the occurrence of bath-related cardiac arrest.

Key words: aging, cardiac arrest, prevention, mortality, weather, cold environment

(Intern Med 56: 3173-3177, 2017)

(DOI: 10.2169/internalmedicine.9156-17)

\section{Introduction}

In an aging society, the burden imposed by lifethreatening conditions increases. Sudden death during bathing frequently occurs in Japan (1-13). Such bath-related deaths have been reported as exceeding $10 \%$ of all sudden deaths (8), and most victims are $\geq 65$ years of age $(1-7,9-13)$. This phenomenon is unique to Japan and is not seen in other developed countries, including the US, UK, Germany, and France (9). Few previous studies have reported the actual death toll $(6,11,12)$. We recently conducted broad surveillance programs in three areas - Tokyo Metropolis, Saga Prefecture, and Yamagata Prefecture - and revealed the nationwide occurrence of an estimated 19,000 deaths annually (11). This sudden death phenomenon is rapidly increasing, since the elderly population ( $\geq 65$ years of age) of Japan is now growing. Because of this phenomenon, the annual number of deaths nationwide is expected to increase to 25,000 by 2025 and to over 27,000 by 2035 (11). We may therefore soon face over 20,000 annual deaths unless an effective means of prevention is established.

To recognize and prevent such fatal events, we must understand the actual situation and associated patient characteristics. Unfortunately, the etiology of bath-related deaths remains unknown. Previous studies have shown that bathrelated deaths typically occur during the winter $(2,5-9,11$, 12). However, the reason why such events occur more frequently in the winter has not been elucidated. In the present study, we hypothesized that the occurrence of bath-related

${ }^{1}$ Department of Emergency and Critical Care Medicine, Keio University School of Medicine, Japan and ${ }^{2}$ Faculty of Science and Technology, Keio University, Japan

Received: March 9, 2017; Accepted: April 4, 2017; Advance Publication by J-STAGE: October 11, 2017

Correspondence to Dr. Masaru Suzuki, internal.med@suzuki.so-net.jp 
Table 1. Items on the Surveillance Card for Emergency Personnel.

\begin{tabular}{ll}
\hline \multicolumn{1}{c}{ Data items } & \multicolumn{1}{c}{ Details } \\
\hline Demographics & Age and Sex \\
\hline Vital signs & $\begin{array}{l}\text { Level of consciousness, heart rate, blood } \\
\text { pressure and body temperature }\end{array}$ \\
\hline Condition & $\begin{array}{l}\text { Cardiac arrest } \\
\text { Survivor in need of help } \\
\text { Acute illness } \\
\text { Injury }\end{array}$ \\
\hline Preceding alcohol ingestion & Yes, No or Unknown \\
\hline Setting of the bathroom & $\begin{array}{l}\text { Home } \\
\text { Communal bath/Hotel/Nursing home }\end{array}$ \\
\hline Actual event site & $\begin{array}{l}\text { In the tub } \\
\text { Outside the tub in the bathroom }\end{array}$ \\
\hline Submersion of victim's face in tub water & Yes or No \\
\hline
\end{tabular}

Table 2. Details of Bath-related Events during a 6-month Period Beginning in October 2012 in Tokyo.

\begin{tabular}{|c|c|c|c|c|}
\hline & \multicolumn{2}{|c|}{$\begin{array}{c}\text { Total } \\
\mathrm{N}=3,624(\%)\end{array}$} & \multicolumn{2}{|c|}{$\begin{array}{c}\text { Elderly ( } \geq 65 \mathrm{y} / \mathrm{o}) \\
\mathrm{N}=2,947(\%)\end{array}$} \\
\hline & In the tub & Outside the tub & In the tub & Outside the tub \\
\hline Total & $2,275(100)$ & $1,349(100)$ & $2,030(100)$ & $917(100)$ \\
\hline Male & $1,354(66)$ & $762(56)$ & $1,102(54)$ & $623(68)$ \\
\hline \multicolumn{5}{|l|}{ Condition } \\
\hline Cardiac arrest & $1,177(52)$ & $98(7)$ & $1,081(53)$ & $66(7)$ \\
\hline Survivor in need of help & $709(31)$ & $56(4)$ & $659(32)$ & $42(5)$ \\
\hline Acute illness & $341(15)$ & $782(58)$ & $268(13)$ & $566(60)$ \\
\hline Injury & $48(2)$ & $410(30)$ & $22(1)$ & $242(26)$ \\
\hline Unknown & $0(0)$ & $3(0)$ & $0(0)$ & $1(0)$ \\
\hline
\end{tabular}

deaths was correlated with a low air temperature.

\section{Materials and Methods}

This prospective cross-sectional observational study was approved by the Ethics Committee of Keio University (20120231). It was conducted between October 2012 and March 2013 in the Tokyo Metropolitan area. We evaluated data collected from all activations of the emergency medical system because of an accident or acute illness related to bathing. Upon recognizing that the activation of the emergency medical system was related to bathing, the emergency personnel were asked to complete a surveillance card to enroll the event in this study (Table 1). The bath-related events were classified into four categories: 1) cardiac arrest (bathrelated out-of-hospital cardiac arrest), 2) a survivor who required help for any reason, 3) any acute illness, and 4) injury.

From the enrolled data, the cardiac arrest events were extracted, and the number of cardiac arrest victims was obtained. Among them, elderly individuals ( $\geq 65$ years of age) who had been found in a bathtub filled with water were further analyzed.

The relationship between the daily number of cardiac ar- rest events and the lowest daily air temperatures in Tokyo was analyzed using a nonlinear regression model and statistical software (SPSS 23.0J). The lowest daily air temperatures in Tokyo were obtained from a report published by the Japan Meteorological Agency (http://www.jma.go.jp/jma/ind ex.html).

\section{Results}

In total, 3,624 bath-related events occurred (Table 2). Among these events, 1,177 led to cardiac arrest. Of those, 1,081 elderly individuals had been found in a bathtub filled with water (Fig. 1 and Table 3). The number of events appeared to increase during months with cold weather (Fig. 2).

A close correlation was observed between the daily number of events and the lowest daily air temperature (Fig. 3). This correlation was described by the following equation:

$$
\mathrm{y}=8.38 \mathrm{e}^{-0.07 \mathrm{x}}
$$

where $\mathrm{y}$ was the daily number of cardiac arrests and $\mathrm{x}$ was the lowest daily air temperature.

\section{Discussion}

This is the first study to report that bath-related deaths are 


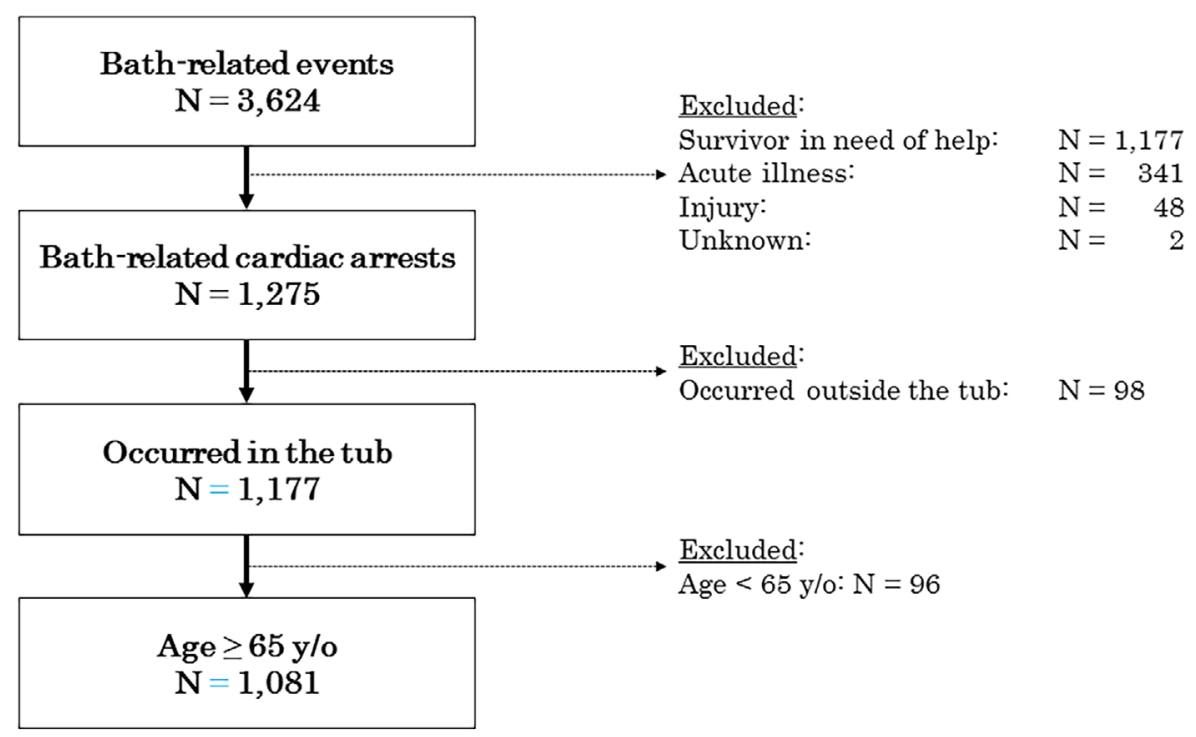

Figure 1. Included and excluded patients in this study.

Table 3. Characteristics of the Included Patients.

\begin{tabular}{lcc}
\hline & $\begin{array}{c}\text { Number of patients } \\
(\%)\end{array}$ & $\begin{array}{c}\text { Number of } \\
\text { unknown and/or } \\
\text { missing data }\end{array}$ \\
\hline Setting of the bathroom & $1,051 / 27$ & 3 \\
Home/other & $(97 \% / 3 \%)$ & 36 \\
Submersion of the victim's face in tub water & $864 / 181$ & 36 \\
yes/no & $(83 \% / 17 \%)$ & 639 \\
Preceding alcohol ingestion & $54 / 388$ & \\
yes/no & $(12 \% / 88 \%)$ & \\
\hline
\end{tabular}

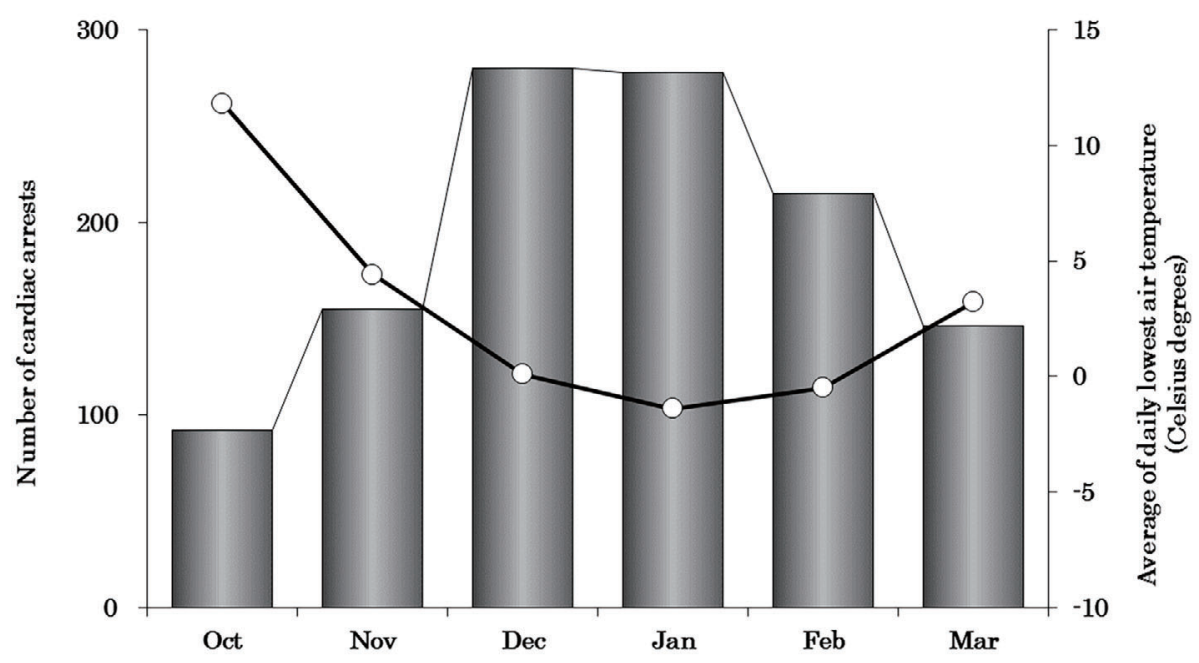

Figure 2. Monthly distribution of the number of bath-related cardiac arrests and the average daily air temperature. Fatal events were more frequent during colder months than during warmer ones.

closely correlated with a low air temperature. This finding may play a crucial role in establishing an effective prevention program against bath-related sudden cardiac arrest.

Previous studies have shown that bath-related deaths typically occur during the winter $(5,7,9,10)$. Although the reason why such events occur more frequently in the winter has not been elucidated, cold environments might be associated with the etiology of bath-related deaths. Generally, a cold environment involves a low temperature, especially in the atmosphere. Therefore, we hypothesized that the occurrence of bath-related deaths was correlated with a low air temperature. 


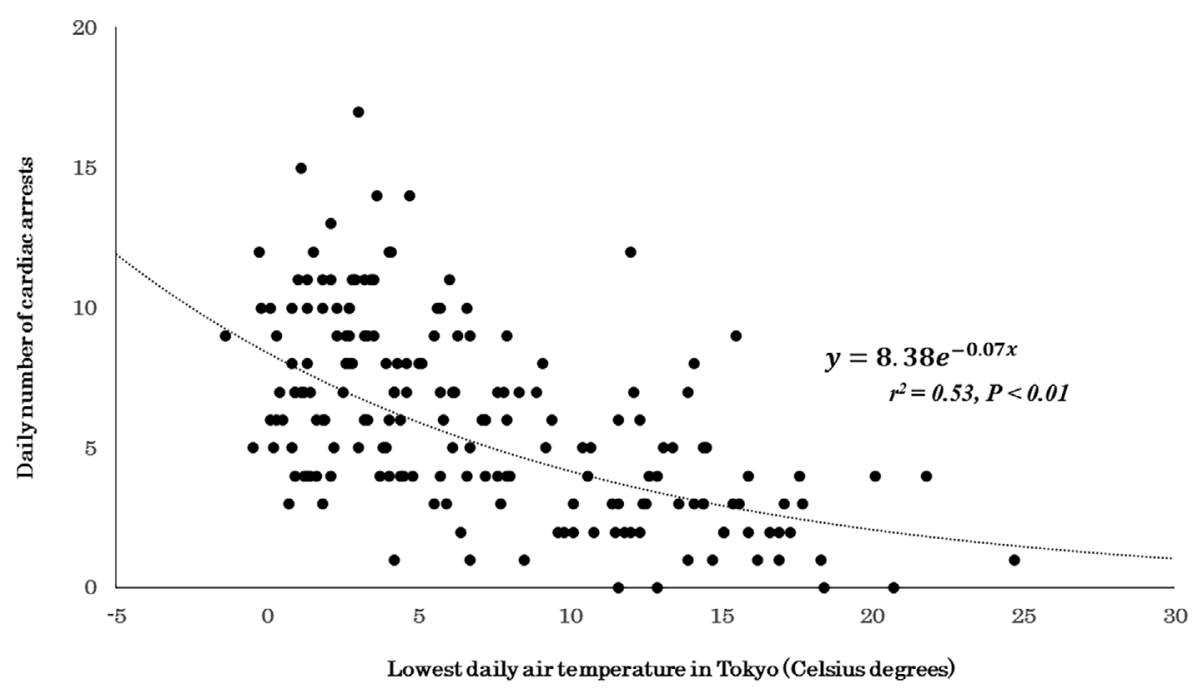

Figure 3. Relationship between the daily number of cardiac arrest events and the lowest daily air temperature in Tokyo. A close correlation was observed between the daily number of events and the lowest daily air temperature.

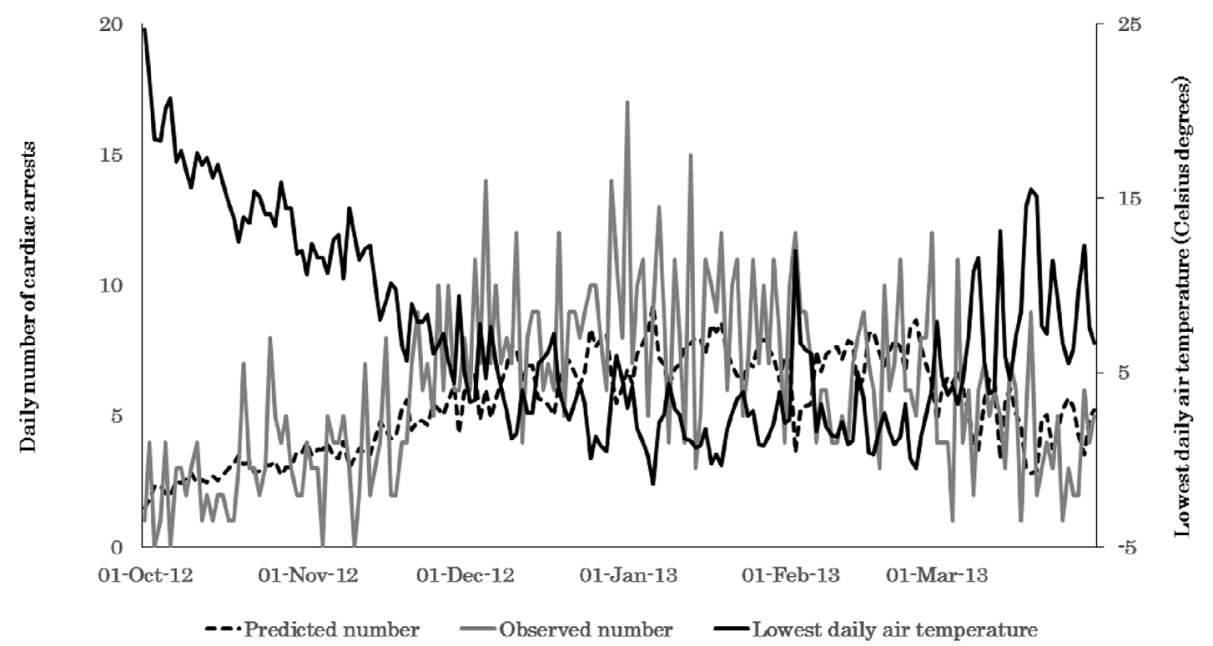

Figure 4. Actual and estimated numbers of cardiac arrests. The solid black line shows the lowest daily temperature in Tokyo, as reported by the Japan Meteorological Agency. The gray line shows the observed number of daily cardiac arrests. The broken line shows the predicted number of cardiac arrests based on the data for the lowest daily air temperature.

This equation accurately reflected the actual number of death events. Using this equation, the total number of elderly patients predicted to experience cardiac arrest while bathing between October 2012 and March 2013 was estimated to be 997, whereas 1,081 cardiac arrests were actually observed during this study (Fig. 4). The equation might also be valuable for other estimations. A previous surveillance program performed in the Tokyo Metropolitan area between October 1999 and March 2000 reported that the Tokyo Fire Department recognized 578 sudden cardiac arrest events that occurred during bathing (6). Using the equation modified by the elderly population data, the total number of elderly patients predicted to have experienced cardiac arrest while bathing during a 6-month period from October 1999 was estimated to be 515 .
The present finding may also play a crucial role in determining why such events occur. In accordance with Japanese bathing customs, hot water immersion is often performed when the weather is cold. A previous study reported that the temperature of bath water is higher in the winter than in the summer (12). Another study reported that water temperature was closely correlated with death in an animal model (14). Therefore, the water temperature might be correlated with such events. Hot water immersion during Japanese-style bathing might cause heat illness, including heat stroke, heat exhaustion, and heat syncope. Our recent study revealed that drowning was strongly correlated with bath-related death (11). This finding suggested that a preceding disturbance of consciousness is a major mechanism, rather than cardiogenic sudden cardiac arrest. Hot water immersion 
might therefore increase an individual's body temperature, leading to a loss of consciousness.

This equation might also help predict days on which frequent fatal events are particularly likely to occur. If the weather forecast predicts a very low daily temperature, then using such predicted temperatures, we could issue an alert for bath-related sudden death events. Such an early warning may be an important preventive strategy. If the weather forecast predicts cold temperatures, the temperature of bathwater and the duration of bathing should be closely monitored.

When establishing a strategy for prevention, focusing only on lethal events leads to unavoidable limitations. The present study had several such limitations. First, a limited geographical area was analyzed. Bathing habits are known to differ according to residential environment. For example, newly constructed houses have a warmer residential environment because of updated building standard acts. In addition, the daily lowest temperature varies markedly throughout Japan. Therefore, the application of the presently reported equation to other geographical areas is likely to be limited. Second, the study period was from October to March. Because these events are uncommon during the summer, our study concentrated on the winter season. This may have led to an inaccurate estimation, especially for hot days. Despite these limitations, this is the first study to note a relationship between bath-related fatal events and a meteorological phenomenon. Further studies investigating individuals living in other areas and including rescued and surviving victims are strongly recommended.

In conclusion, a low air temperature was closely correlated with the occurrence of bath-related cardiac arrest.

This study was approved by the Ethics Committee of Keio University (20120231). This observational study was not enrolled in the Clinical Study Registry System because registration is not compulsory for clinical studies without interventions.

The authors state that they have no Conflict of Interest (COI).

\section{Financial Support}

This work was supported by a Health Labour Sciences Research Grant (2012-2013).

\section{References}

1. Chiba T, Yamauchi M, Nishida N, Kaneko T, Yoshizaki $K$, Yoshioka N. Risk factors of sudden death in the Japanese hot bath in the senior population. Forensic Sci Int 149: 151-158, 2005.

2. Tokyo Metropolitan Geriatric Hospital and Institute of Gerontology. Summary of survey on sudden deaths during bathing among elderly people. [Internet]. [cited 2015 Feb. 1]. Available from: htt p://www.tmghig.jp/J_TMIG/release/pdf/20121221_takahashi.pdf

3. Hayasaka S, Okayama M, Ishikawa S, Nakamura Y, Kajii E. Accidents associated with bathing in home care services for the aged in japan. J Epidemiol 11: 139-142, 2001.

4. Hayasaka S, Shibata Y, Goto Y, Noda T, Ojima T. Bathing in a bathtub and health status: a cross-sectional study. Complement Ther Clin Pract 16: 219-221, 2010.

5. Hayashi T, Ago K, Ago M, Ogata M. Bath-related deaths in kagoshima, the southwest part of Japan. Med Sci Law 50: 11-14, 2010.

6. Hori S, Suzuki M, Ueno K, Sato Y, Kurihara T. [Accidents during bathing]. Nihon Rinsho (Jpn J Clin Med) 71: 1047-1052, 2013 (in Japanese, Abstract in English).

7. Kiyohara K, Nishiyama C, Hayashida S, et al. Characteristics and outcomes of bath-related out-of-hospital cardiac arrest in Japan. Circ J 80: 1564-1570, 2016.

8. Kouno A, Matoba R, Shikata I. A statistical study of sudden cardiac death for past five years in Osaka medical, investigated at the Osaka Medical Examiner's Office. Acta Med Leg Soc (Liege) 39: 205-215, 1989.

9. Satoh F, Osawa M, Hasegawa I, Seto Y, Tsuboi A. "Dead in hot bathtub" phenomenon: accidental drowning or natural disease? Am J Forensic Med Pathol 34: 164-168, 2013.

10. Suzuki H, Hikiji W, Tanifuji T, Abe N, Fukunaga T. Characteristics of sudden bath-related death investigated by medical examiners in Tokyo, Japan. J Epidemiol 25: 126-132, 2015.

11. Suzuki M, Shimbo T, Ikaga T, Hori S. Sudden death phenomena while bathing in Japan - mortality data. Circ J 2017 (Epub ahead of print).

12. Takasaki Y, Ohnaka T, Tochihara Y, Nagai Y, Ito H, Yoshitake S. Environmental and behavioral conditions of bathing among elderly Japanese. J Physiol Anthropol 26: 235-240, 2007.

13. Yoshioka N, Chiba T, Yamauchi M, Monma T, Yoshizaki K. Forensic consideration of death in the bathtub. Leg Med (Tokyo) 5 (Suppl 1): S375-S381, 2003.

14. Suzuki M, Hori S. Experimental investigation in rats to identify the cause of sudden death during bathing in Japan. Acute Med Surg 1: 101-104, 2014.

The Internal Medicine is an Open Access article distributed under the Creative Commons Attribution-NonCommercial-NoDerivatives 4.0 International License. To view the details of this license, please visit (https://creativecommons.org/licenses/ by-nc-nd/4.0/).

(C) 2017 The Japanese Society of Internal Medicine Intern Med 56: 3173-3177, 2017 